\title{
The Role of Counter-Ions in Crystal Morphology, Surface Structure and Photocatalytic Activity of ZnO Crystals Grown onto a Substrate
}

Ariadne C. Catto, ${ }^{1,2^{*}}$ Mateus M. Ferrer, ${ }^{3}$ Osmando F. Lopes, ${ }^{4,5}$ Valmor R. Mastelaro, ${ }^{6}$ Juan Andrés, ${ }^{7}$ Luís F. da Silva, ${ }^{2}$ Elson Longo ${ }^{1}$ and Waldir Avansi Jr. ${ }^{2}$

1 - CDMF, Federal University of São Carlos, Rodovia Washington Luiz, km 235,13565-090, São Carlos, SP, Brazil.

2 - Laboratory of Nanostructured Multifunctional Materials, Federal University of São Carlos, Rodovia Washington Luiz, km 235,13565-090, São Carlos, SP, Brazil.

3 - Institute of Exact Science, Federal University of Amazonas, 69077-000, Manaus, AM, Brazil.

4- Laboratory of Photochemistry and Materials Science, Institute of Chemistry, Federal University of Uberlândia, 38400-902, Uberlândia, MG, Brazil

5-Forschungszentrum Jülich GmbH, Institute of Energy and Climate Research (IEK-14): Electrochemical Process Engineering, Jülich 52425, Germany

6- Institute of Physics of São Carlos, University of São Paulo, Avenida Trabalhador São Carlos, 13566590, São Carlos, SP, Brazil

7 - Departmento Química-Física y Analítica, Universitat Jaume I, Castelló E-12080, Spain

*E-mail: ade.catto@gmail.com

\begin{abstract}
In this contribution, we present an experimental and theoretical investigation of the role of counter-ions in the crystal morphology, surface structure, and photocatalytic activity of hierarchical $\mathrm{ZnO}$ nanostructures. The effect of zinc precursor (nitrate, acetate and, sulfate) along the synthesis of $\mathrm{ZnO}$ nanostructures grown directly onto a substrate by means of a simple hydrothermal method was analyzed in detail. Scanning electron microscopy images showed a preferential growth of $\mathrm{ZnO}$ nanostructures along the caxis, with a slight reduction in the orientation depending on the choice of the $\mathrm{Zn}$ source.
\end{abstract}


Theoretical calculations based on Wulff theory allowed us a better understanding of the morphological changes and to directly relate the photocatalytic performance at the different exposed surfaces of the as-observed crystal shapes. Our results showed that photocatalytic activities in the discoloration of organic dyes became superior for hierarchical $\mathrm{ZnO}$ nanostructures obtained from zinc nitrate. This finding was explained by X-ray photoelectron and photoluminescence spectroscopies, which revealed that the presence of surface defects, as well as the attached counter-ions and the abundance of carboxylate groups and organic residuals on $\mathrm{ZnO}$ surfaces are determinant for enhanced photocatalytic performance.

KEYWORDS: Nanostructures; Hierarchical ZnO; hydrothermal; crystal morphology; photocatalysis; Wulff model.

\section{Introduction}

Nowadays, a concern over environmental problems has enhanced our awareness of the need to develop an alternative and environmentally-friendly process to increase environmental protection [1-8]. Heterogeneous photocatalysis is considered one of the most promising and sustainable way to treat waste water and degrade organic pollutants due to its high efficiency, low toxicity, low cost and eco-friendly characteristic [9-11]. Despite the advantages of heterogeneous photocatalysis using powder-form metal oxide (MOX) semiconductors, such catalysts have major drawbacks regarding their recovery and reuse of powder photocatalysts, discouraging their application in large water purification systems $[12,13]$. An interesting alternative is the use of photocatalysts based on MOXs to form thick and/or thin films for practical applications [14-17]. 
Among the MOXs investigated as heterogeneous photocatalysts, zinc oxide ( $\mathrm{ZnO})$ has exhibited favorable optical, electronic and surface properties, appearing as a promising candidate in the photocatalysis area due to its green and sustainable technology [14,18-23]. Because of its unique characteristics, such as direct and wide band gap in the near-UV spectral region $\left(\mathrm{E}_{\mathrm{g}}=3.2 \mathrm{eV}\right.$, at $\left.300 \mathrm{~K}\right)$, strong oxidation ability and a large free-exciton binding energy, $\mathrm{ZnO}$ has been considered a compelling choice for environmental waste management systems [19,24-27].

Over the past decade, several synthesis methodologies have been used to explore and optimize the $\mathrm{ZnO}$ compound, allowing the obtainment of a variety of properties with precise control over the morphological features [16,22,23,28-30]. Among such routes, the conventional hydrothermal treatment has several advantages related to its technical convenience in obtaining well-structured $\mathrm{ZnO}$ crystals grown directly onto a substrate by means of relatively low-temperature treatment [30-35]. The morphological and surface properties of these nanostructures can be controlled by the optimization of some synthesis parameters, such as precursor concentration, source (distinct counterions), solvent, temperature and reaction time, among others [29,30,33,35-39].

It is known that crystal morphology influences considerably the final material properties. In various research fields, the performance of the devices is completely described by the morphology, type and relative area of the exposed surfaces $[40,41]$. In catalysis, for example, different crystal facets often have distinct catalytic activity, making it possible to improve their performance by exposing the catalyst facet of higher activity. The morphology of $\mathrm{ZnO}$ has been widely studied and critically analyzed with respect to its application in photocatalytic and antibacterial phenomenon [42-47].

Physical-chemical properties, such as crystalline structure, orientational texture, electronic properties, presence of dopants/impurities, crystal morphology and surface 
features, play a significant role in the (photo)catalyst performance [22-24,29,48,49]. Boppella and co-workers [48] reported that a greater fraction of the exposed polar surfaces of $\mathrm{ZnO}$ prepared by the hydrothermal method leads to an enhancement of the photocatalytic performance. Additionally, it was demonstrated that the photocatalytic properties of materials are very dependent on their surface architectures [49]. In particular, $\mathrm{ZnO}$ with a large ratio of (0001) planes exhibits enhanced photocatalytic performance, such as the degradation of organic pollutants [47,50-54]. However, such studies are limited to powdered MOXs. Thus, there is still much room for the development of catalyst-coated thin films with controlled exposed facets. With regards to $\mathrm{ZnO}$ compound, the wide range of different morphologies has made it a distinctive candidate to be further studied. In this way, the understanding of the relationship between $\mathrm{ZnO}$ surface structure and performance may offer new opportunities for the construction of $\mathrm{ZnO}$-based nanomaterials with high photocatalytic activity.

The detailed understanding of the properties of the materials often requires a deeper level of structural and electronic detail than the ones provided by current techniques. For this purpose, the use of theoretical simulations has been frequently used for a deep investigation of the bulk and the surface characteristics of the materials, which includes the $\mathrm{ZnO}[55,56]$. In past years, our group has been used the Wulff theory along with quantum models as a simple and powerful tool to evaluate the different types of growth and changes in the surface energy of the material [57-60]. Briefly, the Wulff theory presents a simple method to estimate the morphology from the surface energy of crystalline systems [61]. The relationship between theory and experiment based on this methodology allows a good understanding of the routes of morphological changes observed in experiments as well the correlation with the properties modifications [59]. 
Based on these arguments, we report herein the investigation on the role of counter-ions (zinc nitrate, acetate, and sulfate) in the structural, surface and photocatalytic properties and crystal shape of $\mathrm{ZnO}$ thick films grown via hydrothermal treatment. The microstructural and surface properties were investigated by X-ray diffraction (XRD), field emission scanning electron microscopy (FE-SEM), photoluminescence (PL) spectroscopy and X-ray photoelectron spectroscopy (XPS) techniques. The photocatalytic performance was monitored using methylene blue (MB) and rhodamine $\mathrm{B}(\mathrm{RhB})$ dyes under UV light activation. The use of $\mathrm{MB}$ and $\mathrm{RhB}$ dyes was motivated because they are two of the most common chemicals used in industrial production methods and often causes environmental pollution as well as their easy spectrophotometric monitoring [62]. To complement and rationalize the experimental results, theoretical calculations based on Wulff theory were made to directly probe at the atomic level the location of photocatalytic activity at the different exposed surfaces of the as-observed morphologies.

\section{EXPERIMENTAL SECTION}

\subsection{Preparation of $\mathrm{ZnO}$ nanostructures.}

The growth of $\mathrm{ZnO}$ nanostructures was achieved by hydrothermal treatment of different precursors. Three different zinc precursors were studied: zinc nitrate $\left(\mathrm{Zn}\left(\mathrm{NO}_{3}\right)_{2} 6 \mathrm{H}_{2} \mathrm{O}\right)$, zinc acetate $\left(\mathrm{Zn}\left(\mathrm{CH}_{3} \mathrm{COO}\right)_{2} 2 \mathrm{H}_{2} \mathrm{O}\right)$, and zinc sulfate $\left(\mathrm{ZnSO}_{4} 7 \mathrm{H}_{2} \mathrm{O}\right)$. All precursors were obtained from Sigma-Aldrich (USA) and used without any further purification. The growth of hierarchical $\mathrm{ZnO}$ nanostructures were performed onto a crystalline $\mathrm{ZnO}$ thin film. A nanocrystalline $\mathrm{ZnO}$ thin film, which acted as a seed layer, were prepare via the polymeric precursor method and deposited onto a pre-cleaned borosilicate glass substrate via spin-coating technique, as previously described in reference 31. First, 
$0.055 \mathrm{M}$ of zinc salt (nitrate, acetate, or sulfate) and hexamethylenetetramine $\left(\mathrm{C}_{6} \mathrm{H}_{12} \mathrm{~N}_{4}\right.$, HMTA, Aldrich, $>99 \%$ ) in a molar concentration of $0.1 \mathrm{M}$ were dissolved in deionized water at room temperature under continuous stirring. This reaction solution was then dropped into an autoclave (screw-capped bottle), and the seed layer was carefully immersed in this solution, assuring that the $\mathrm{ZnO}$ seed layer is facing down.

Nanostructured $\mathrm{ZnO}$ thick films were hydrothermally grown by holding the autoclave in a conventional electric oven for $4 \mathrm{~h}$ at $110{ }^{\circ} \mathrm{C}$ with a heating rate of $10{ }^{\circ} \mathrm{C} \min ^{-1}$. At the end of the hydrothermal treatment, the sample was then removed from the solution and washed several times with deionized water and isopropyl alcohol. Finally, the sample was dried on an electric oven for $12 \mathrm{~h}$ at $80{ }^{\circ} \mathrm{C}$. The samples were labeled according to the precursor employed: Zn_Nit (nitrate), Zn_Ace (acetate), and Zn_Sul (sulfate).

\subsection{Materials characterization}

X-ray diffraction patterns were determined using a Rigaku diffractometer (model ULTIMA IV, Japan, CuKa radiation) operating in Bragg configuration. The data were collected in the range of $2 \theta=20$ to $80^{\circ}$ with a step of $0.02^{\circ}$ at a scanning speed of $2^{\circ}$ $\min ^{-1}$. The microstructural properties of the $\mathrm{ZnO}$ nanostructures were analyzed using a field emission scanning electron microscope (FE-SEM, Zeiss Supra35) operating in different magnifications. The average size of the $\mathrm{ZnO}$ structures was estimated by measuring at least 300 particles from the FE-SEM micrographs. X-ray photoelectron spectroscopy (XPS) spectra were collected on a Thermo Scientific K-Alpha spectrometer (USA) using a monochromatic AlK $\alpha$ X-ray source. The spectra had their peak fitted using the Casa XPS software, and all binding energies were given with reference to the $\mathrm{C}$ 1s signal $(284.9 \mathrm{eV})$ arising from the surface hydrocarbons. Room- 
temperature photoluminescence spectra were collected using a Thermal Jarrel-Ash Monospec 27 monochromator and a Hamamatsu R446 photomultiplier linked with a data acquisition system consisting of a SR-530 lock-in controlled by microcomputer. All the samples were excited by $350 \mathrm{~nm}$ wavelength light from a krypton ion laser (Coherent Innova) and the nominal output power of the laser was kept at $200 \mathrm{~mW}$.

\subsection{Photocatalytic experiments}

The catalytic performance of the photocatalysts was probed by the oxidation of methylene blue $(\mathrm{MB})$, and rhodamine $\mathrm{B}(\mathrm{RhB})$ dyes under UV light. Rectangular samples (area of approximately $60 \mathrm{~mm}^{2}$ ) were immersed in $10 \mathrm{~mL}$ of an aqueous $\mathrm{MB}$ dye solution, $10 \mathrm{mg} \mathrm{L}^{-1}$, and $\mathrm{RhB}$ dye solution, $5 \mathrm{mg} \mathrm{L}^{-1}$. The solution containing the photocatalysts was placed into a photo reactor at controlled temperature $\left(20^{\circ} \mathrm{C}\right)$ and illuminated by six UV lamps (TUV Philips, $15 \mathrm{~W}$, and maximum intensity at $254 \mathrm{~nm}$ ) with an optical irradiance of approximately $35 \mathrm{~mW} \mathrm{~cm}^{-2}$.

The color removal of the dye solutions was monitored by measuring their UV-Vis spectra (Shimadzu-UV-1601 PC spectrophotometer, Japan, with $\lambda_{\max }=663$, and $554 \mathrm{~nm}$, for $\mathrm{MB}$, and $\mathrm{RhB}$ dyes, respectively) at different times of light exposure. To test the direct UV-photolysis of the dye, blank experiments were performed using an MB, and $\mathrm{RhB}$ dye solution without any catalyst. Before the experiments, the suspensions were left in darkness for $1 \mathrm{~h}$ to establish the adsorption-desorption equilibrium of the dyes on the catalyst surface. The results revealed that the color removal through the adsorption process could be neglected.

\subsection{Computational method and model system.}

An equilibrium morphology model was estimated from the calculated surface energies reported by $\mathrm{Na}$ and Park [63]. In their study, the surfaces were modeled by combining 
the $\mathrm{PBE}+\mathrm{U}$ with projector augmented wave implemented in VASP package [64]. The morphology and possible modification routes according to the surface energy modulation were determined based on Wulff theory, which minimizes the total surface energy at a fixed volume. The Wulff theorem provides a simple relationship between the surface energy $\left(E_{\text {surf }}\right)$ of a plane and its respective distance from the center of the particle [61]. The strategy of modulating the surface energies to describe the morphology changes observed in experimental data has been successful performed by our group $[60,65,66]$. This procedure is considered a powerful tool for understanding the superficial stabilizations caused by the modification in some synthesis parameters. For the development of the different crystal shapes, we used here the Visualization for Electronic and Structural Analysis (VESTA) software [67].

\section{Results and Discussion}

\subsection{Microstructural properties}

XRD patterns of the as-obtained $\mathrm{ZnO}$ samples ( $\mathrm{Zn} \_$Nit, $\mathrm{Zn} \_$Ace, and $\mathrm{Zn} \_$Sul), Fig. 1, show that all reflections can be indexed to a hexagonal wurtzite structure of $\mathrm{ZnO}$ with the $P 6_{3} m c$ space group, according to the Joint Committee on Powder Diffraction Standards (JCPDS) File 36-1451. As it can be seen, all studied samples exhibited a strong (002) peak, revealing a preferential texturing along polar surfaces, typical of $\mathrm{ZnO}$ structures obtained via hydrothermal treatment $[68,69]$. However, in the Zn_Sul sample we could observe the presence of peaks related to a hexagonal wurtzite structure and further peaks assigned to the $6 \mathrm{Zn}(\mathrm{OH})_{2} \mathrm{ZnSO}_{4} 4 \mathrm{H}_{2} \mathrm{O}$ phase (JCPDS File 11-0280). This structural modification indicates that the presence of sulfide ions during hydrothermal treatment did not create favorable conditions to form the pristine $\mathrm{ZnO}$ phase $[37,70,71]$; considering the Zn molar concentration here studied. Wang and co-workers investigated the effect of $\mathrm{ZnSO}_{4}$ molar concentration on $\mathrm{ZnO}$ crystals grown by electrochemical 
deposition. They identified a spurious phase related to sulfur oxides in the $\mathrm{ZnO}$ samples synthesized from $0.6 \mathrm{mM} \mathrm{ZnSO}_{4}$. According to these authors, $\mathrm{SO}_{4}{ }^{2-}$ anions can affect the $\mathrm{ZnO}$ microstructural properties depending on their molar concentration [37].

We should here note that due to the high intensity of (002) peak, the presence of other peaks was not clearly evidenced in Fig.1. Thus, Fig.S1 displays a detailed view of the XRD patterns, indicating the existence of additional peaks related to $\mathrm{ZnO}$ phase. Despite the texture along the c-axis, the polycrystalline feature of the hierarchical $\mathrm{ZnO}$ structures grown onto substrate via hydrothermal treatment has been commonly observed $[68,69,72-75]$.

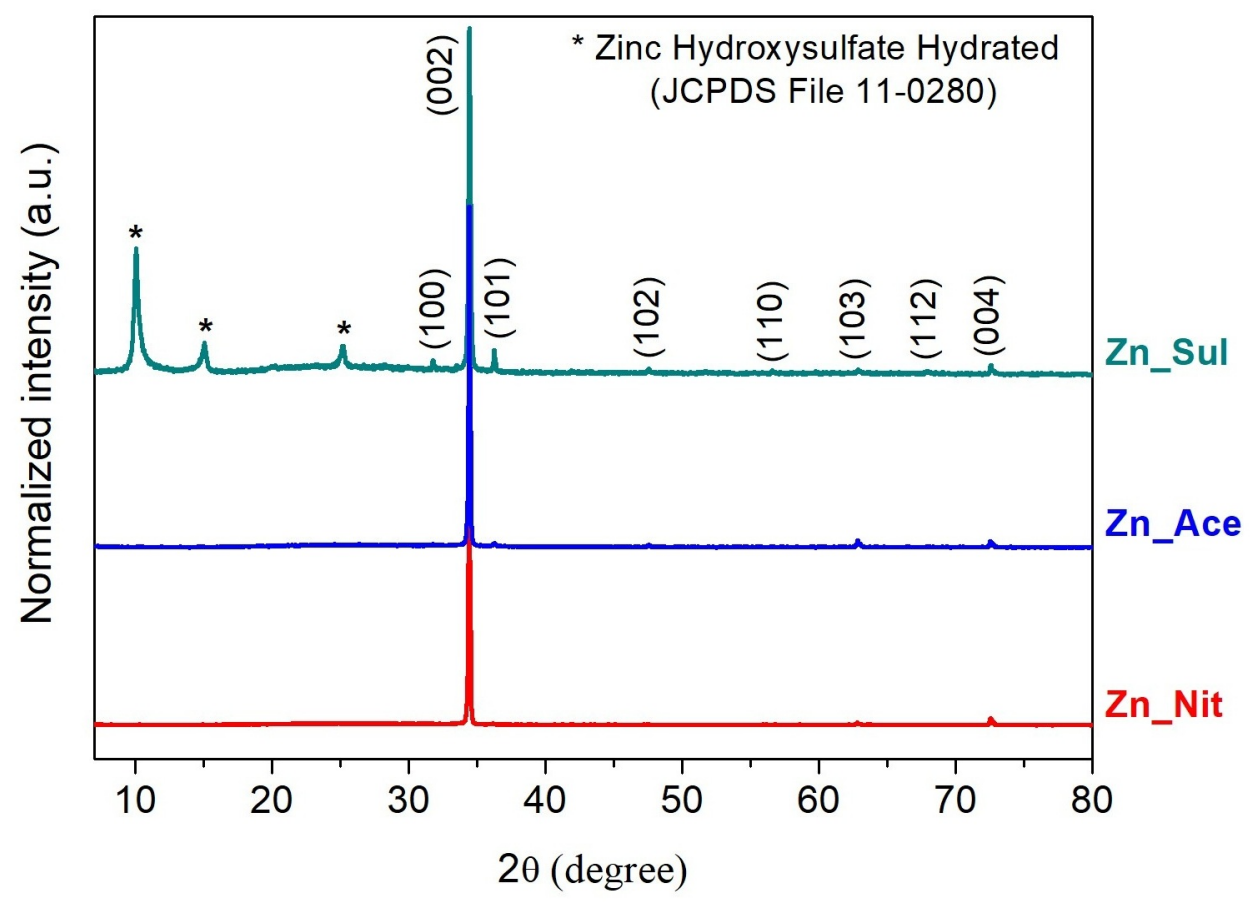

Fig. 1. XRD patterns of $\mathrm{ZnO}$ samples prepared via hydrothermal treatment using different zinc precursors.

Fig. 2(a-i) display the FE-SEM micrographs of the hierarchical $\mathrm{ZnO}$ structures synthesized using different zinc salts. As it can be seen in Fig. 2(a-f), a $\mathrm{ZnO}$ rod-like 
morphology was obtained when nitrate and acetate precursors were used during hydrothermal treatment. The growth of such anisotropic structures - preferentially along the [001] direction - is in accordance with XRD analyses and previous studies employing a similar methodology $[17,68,73-75]$.

The average rod diameter was estimated from the analysis of FE-SEM images, and the values obtained were ca $(188 \pm 20) \mathrm{nm}$ for $\mathrm{Zn} \_$Ace and $(92 \pm 13) \mathrm{nm}$ for Zn_Nit, respectively. In addition, the Zn_Ace sample presented a more homogeneous and evenly distributed rod-like morphology, see Figure $2 \mathrm{e}$ and f. On the other hand, the morphology of Zn_Sul differed from that of Zn_Nit and Zn_Ace, since it was possible to obtain micrometric hexagonal plate-like structures, as displayed in Fig.2 (g-i).

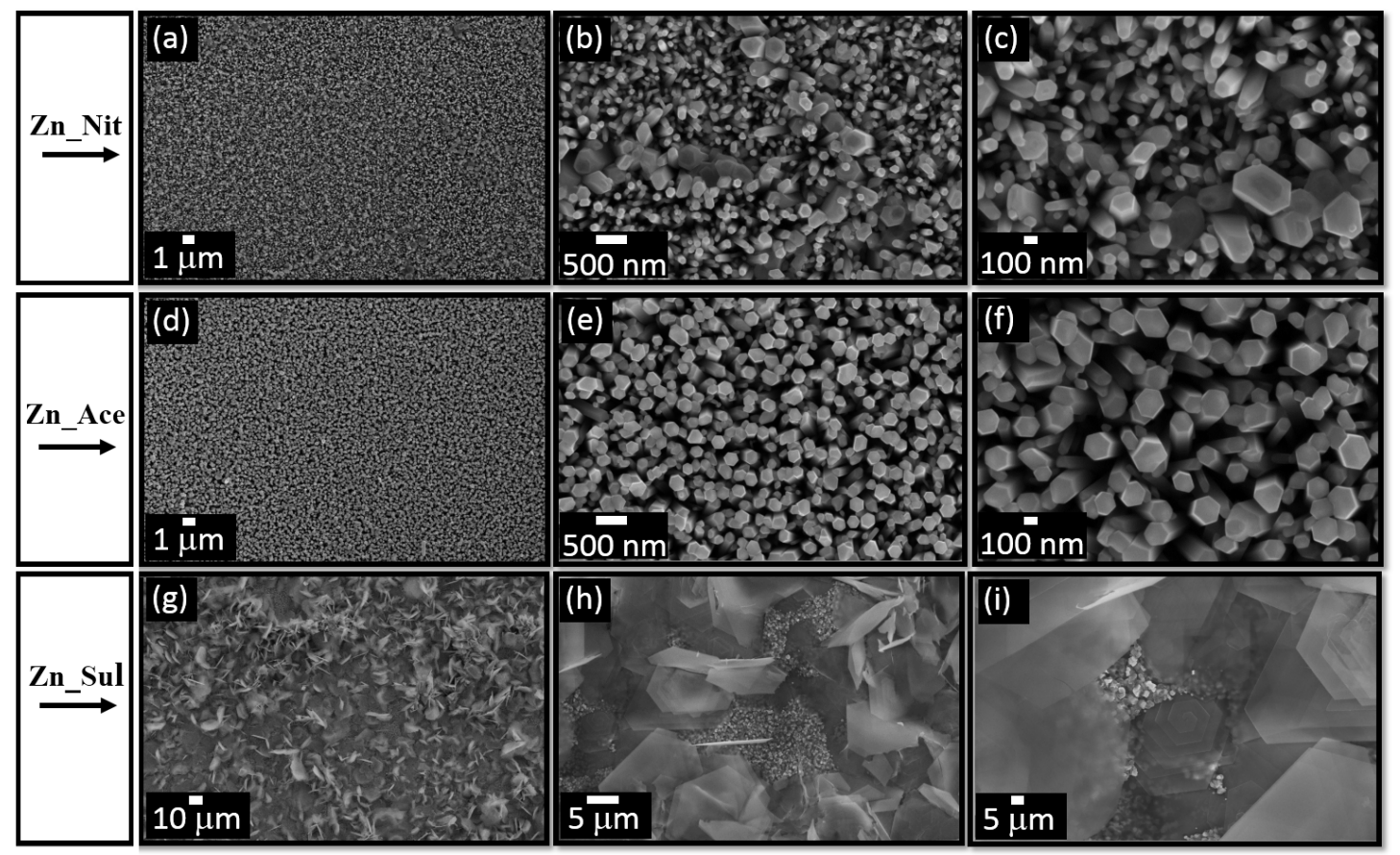

Figure 2. FE-SEM images of hierarchical $\mathrm{ZnO}$ nanostructures found in the (a-c) $\mathrm{Zn}$-Nit, (d-f) Zn_Ace and (g-i) Zn_Sul samples at various magnifications.

According to the literature, during the hydrothermal treatment the sulfide ions appear to have distinct effects to control the $\mathrm{ZnO}$ crystal-morphologies [76]. Alenezi 
and co-workers also reported the effect of counter-ions on the final morphology of $\mathrm{ZnO}$ nanostructures [77]. They attributed the different morphologies, obtained from the use of $\mathrm{SO}_{4}{ }^{2-}$ and $\mathrm{NO}_{3}{ }^{-}$anions, to the ability of these counter-ions to cap the polar surface of the growth of $\mathrm{ZnO}$ structures [77]. The $\mathrm{SO}_{4}{ }^{-2}$ counter-ions could be adsorbed on the (0001) surface, consequently suppressing the anisotropic growth of $\mathrm{ZnO}$ along the [0001] direction, resulting in hexagonal plate-like structures [77]. In a study dedicated to the growth of $\mathrm{ZnO}$ structures via electrochemical method, Wang and co-workers reported that during the deposition process, such $\mathrm{SO}_{4}{ }^{-2}$ ions act as an effective agent controlling the phase evolution of films from rod-like $\mathrm{ZnO}$ to plate-like zinc hydroxysulfate [37]. This fact can explain the morphological modifications observed in our sample by FE-SEM analyses, since XRD pattern show that Zn_Sul sample contains two coexistent crystalline phases.

\subsection{Photocatalytic performance and surface properties}

The photocatalytic performance of the samples was probed with respect to their ability to catalyze the photooxidation of the following organic pollutants: $\mathrm{MB}$ and $\mathrm{RhB}$ dyes. Both kinds of dye were evaluated to demonstrate the versatility of $\mathrm{ZnO}$ samples in the oxidation of different organic pollutants. The net charge (neutral, cationic and anionic) of an organic pollutant and the surface charge of a photocatalyst can influence the photooxidation process, since the interactions between the organic molecule and the photocatalyst are possibly completely different. While the MB dye forms cationic species as it is solubilized in water, the $\mathrm{RhB}$ dye is found to be a zwitterionic molecule in the 7-9 $\mathrm{pH}$ range; therefore, the net charge in the solution is expected to be zero $[78,79]$. 
The photooxidation curves of the MB dye catalyzed by as-obtained samples under UV irradiation are shown in Fig. 3(a). The photolysis directly exhibited a discoloration percentage of the MB dye of about $15 \%$ after 120 min under UV exposure. It can be seen that the all samples were photoactive, since their kinetic curves decreased faster than the direct photolysis curve, see Fig. 3. The rate of MB dye degradation catalyzed by $\mathrm{ZnO}$ samples followed the order: $\mathrm{Zn} \_\mathrm{Nit}>\mathrm{Zn} \_$Ace $>\mathrm{Zn}$ _Sul, where the reaction rate constants, calculated using the pseudo-first-order model, were 3.1, 2.1 and 1.9 (.x $10^{-3}$ min..$\left.^{-1}\right)$, respectively. A similar behavior was also observed for the photooxidation of the $\mathrm{RhB}$ dye, as seen in Fig. 3(b), whose reaction rate constants were equal to 2.6, 1.3 and 1.03 ( $\left.\mathrm{x} 10^{-3} \mathrm{~min}^{-1}\right)$, respectively. Therefore, these findings indicated that $\mathrm{ZnO}$ thick films are unselective for the oxidation of organic pollutants, i.e., $\mathrm{ZnO}$ samples can effectively be applied as catalysts for the degradation of organic pollutants with different net charge.

(a)

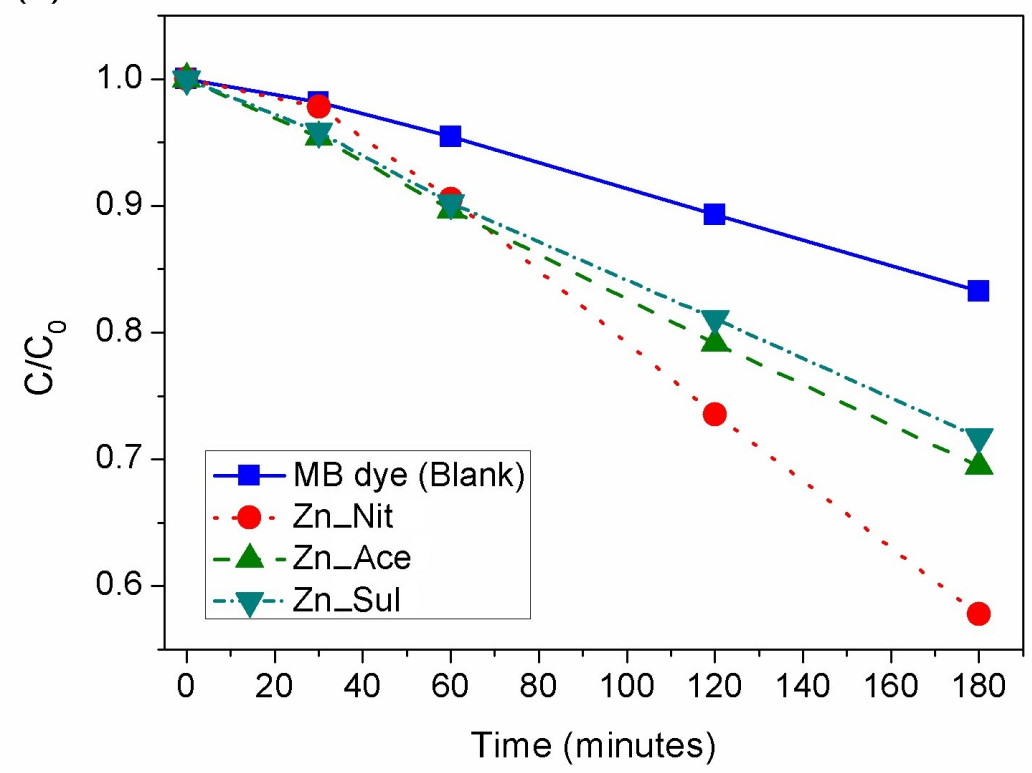




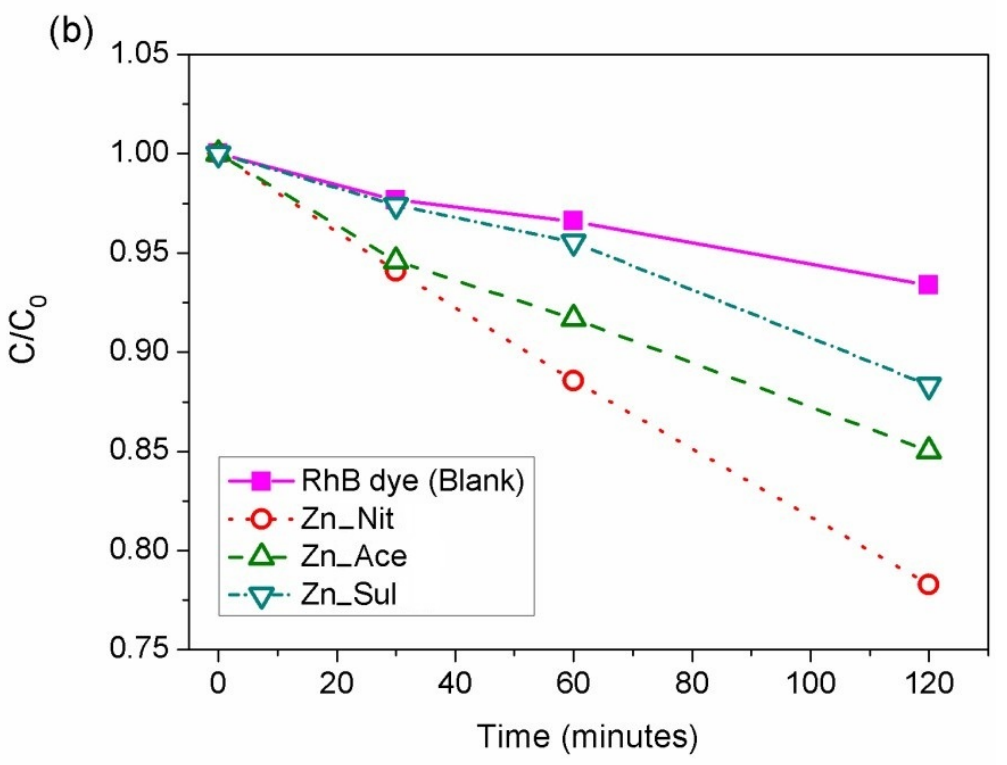

Figure 3. Kinetics of the photooxidation of (a) MB and (b) RhB dyes catalyzed by Zn_Nit, Zn_Ace, and Zn_Sul samples.

About the mechanism responsible for organic pollutant oxidation, it can occurs by two main mechanism, direct and indirect oxidation [80-84]. In the direct oxidation when an electron-hole pair is formed by irradiation, the hole will migrate to the material surface, oxidizing the adsorbed compound on the semiconductor surface, while in the indirect oxidation, the electron-hole pair acts to form free radicals $\left({ }^{\cdot} \mathrm{OH}, \mathrm{O}_{2}^{-\cdot}\right)$ from surface groups $[79,85]$. Therefore, the direct oxidation tends to be a selective process, since occurs by adsorption of compounds in semiconductor surface. Therefore, as $\mathrm{ZnO}$ samples were unselective to degrade different kind of organic pollutant ( $R h B$ and $M B$ ), it is expected that indirect mechanism played the main role. Additionally, it was already showed that $\mathrm{ZnO}$ was able to generate ${ }^{\circ} \mathrm{OH}$ radical and this specie was responsible for organic pollutant oxidation, in according with our results [86].

In order to gain a deep insight into the relationship between surface properties and photocatalytic activities, the as-prepared samples were analyzed by XPS technique. The XPS survey spectra of the Zn_Nit, Zn_Ace and Zn_Sul samples are illustrated in Fig 4(a). The peaks in these spectra were indexed and revealed the presence of $\mathrm{Zn}, \mathrm{O}$ 
and $\mathrm{C}$, respectively. In addition, the Zn_Sul sample also presented further impurities, attributed to $\mathrm{SO}_{4}^{2-}$ anions from the zinc precursor, as previously discussed.

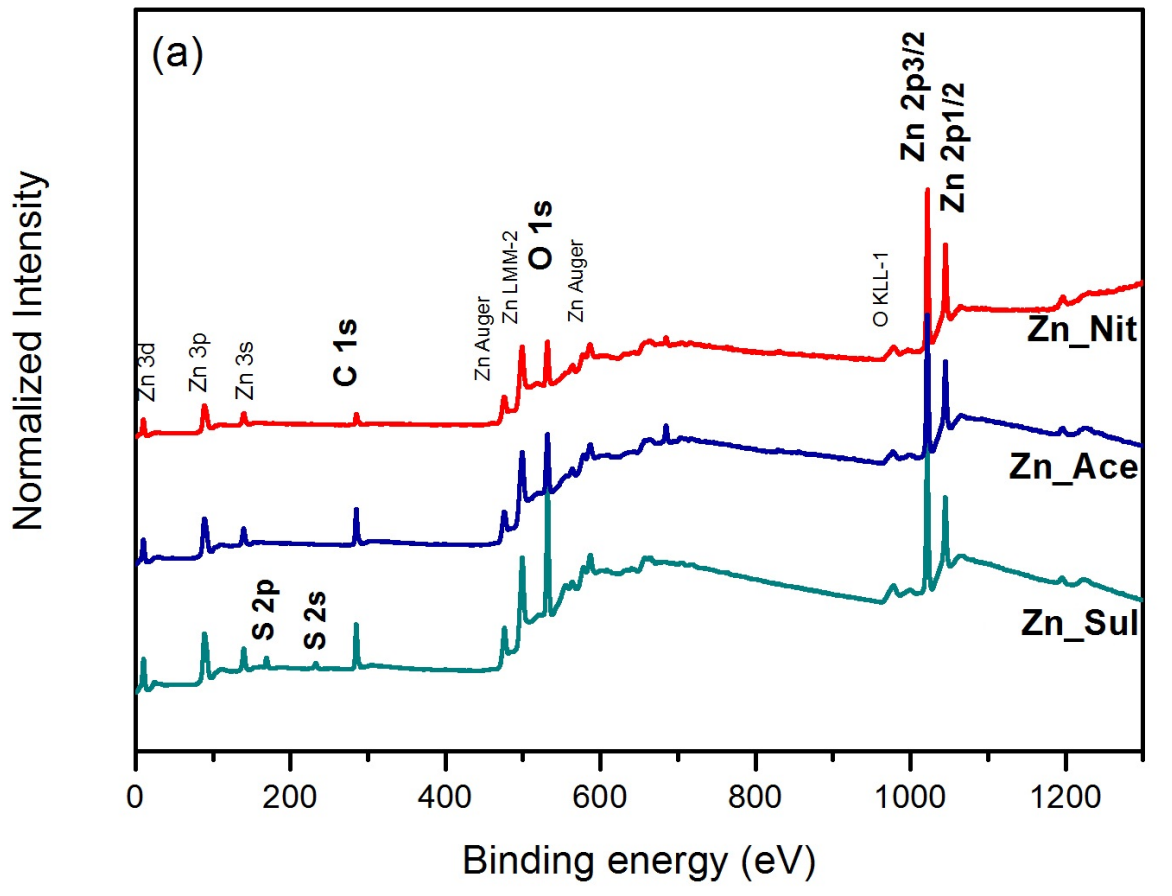



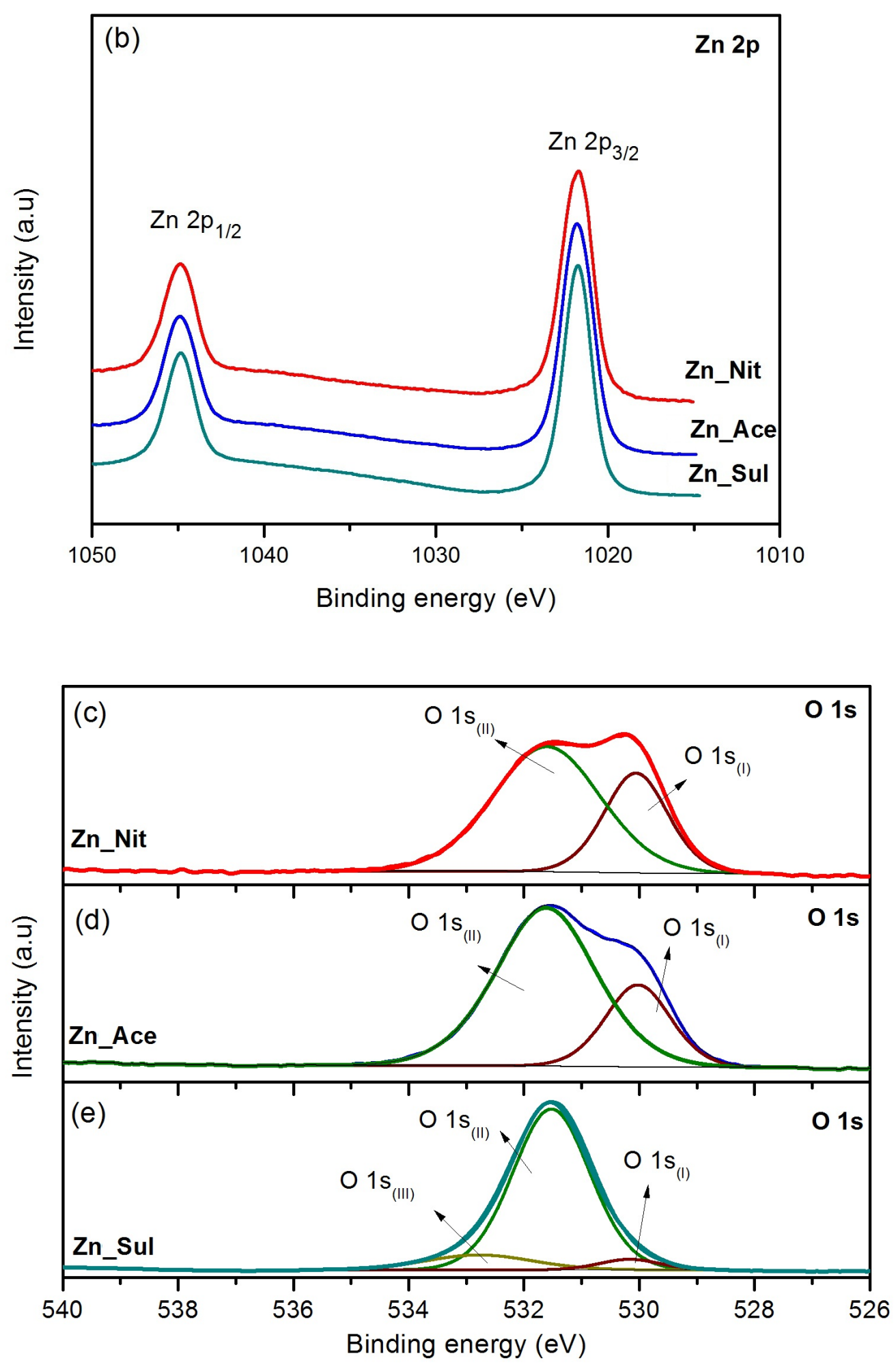

Figure 4 - XPS spectra of $\mathrm{ZnO}$ nanostructures obtained using different $\mathrm{Zn}$ precursors. (a) Survey scan, (b) Zn 2p level, and (c)-(e) O 1s level. 
In high-resolution $\mathrm{Zn} 2 p_{3 / 2}$ XPS spectra, Fig. 4(b), the peak at ca. $1021.7 \mathrm{eV}$ confirmed the presence of $\mathrm{Zn}^{2+}$ cations $[87,88]$. The high-resolution $\mathrm{O} 1 \mathrm{~s}$ spectra deconvoluted into Gaussian-Lorentzian components, as illustrated in Fig. 4(c-e). The analysis revealed the presence of two oxygen species, labeled as $\mathrm{O}_{1 \mathrm{s( \textrm {I } )}}$ and $\mathrm{O}_{1 \mathrm{s(II)}}$, in the Zn_Nit and Zn_Ace samples. Additionally, an additional component (labeled as $\mathrm{O}_{1 \mathrm{~s}(\mathrm{III})}$ ) was found only in $\mathrm{Zn}$-Sul, which corresponds to the $\mathrm{SO}_{4}{ }^{2-}$ anion. While the peak at $530.1 \mathrm{eV}\left(\mathrm{O}_{1 \mathrm{s(I})}\right)$ is attributed to the oxygen located in the lattice, the second $\mathrm{O}_{\text {1s(II) }}$ component is assigned to chemical functional groups, such as carboxyl, acetal and hydroxyl $[89,90]$.

The hydroxyl groups found on the surface of the samples might have trapped in the photogenerated holes to form hydroxyl radicals, possibly suppressing electron-hole recombination and contributing to an improvement of the photocatalytic activity [91]. The analysis of the XPS spectra indicated that the percentage of the $\mathrm{O}_{\text {1s(II) }}$ components is the highest in all samples investigated, with a percentage value between 66.1 and $84.5 \%$, as presented in Table 1. The $\mathrm{O}_{1 \text { (II) }}$ component is assigned to surface hydroxyl groups (metal-OH bond), commonly associated with the photocatalytic activity enhancement [92]. However, the percentage value of the $\mathrm{O}_{\text {1s(II) }}$ component here obtained is not enough to link the higher photocatalytic efficiency observed in the Zn_Nit sample to the hydroxyl groups, since this was the sample that presented the lowest percentage of the $\mathrm{O}_{1 \text { (II) }}$ component. According to the literature, the component located at approximately $531.5 \mathrm{eV}$ has also been related to $\mathrm{C}=\mathrm{O}$ and $\mathrm{C}-\mathrm{O}$ bonds in chemical functional groups, such as carboxyl and acetal $[18,89,93,94]$. Therefore, the increase in the percentage value of the $\mathrm{O}_{1 \mathrm{~s}(\mathrm{II})}$ component may also suggest a high percentage of carboxylate groups from the zinc precursor, Table S1, which poisoned the photocatalyst surface, consequently affecting the photocatalytic performance for the discoloration of organic dyes. Regarding the $\mathrm{Zn}$ _Sul 
sample, the lowest photocatalytic activity can be possibly related to the presence of a spurious phase.

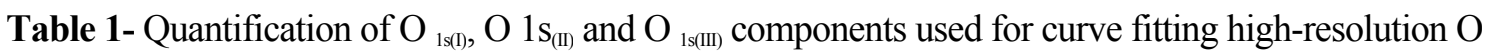
1s XPS signals and their binding energies (BEs).

\begin{tabular}{|c|c|c|c|}
\hline & \multicolumn{3}{|c|}{ O 1 s components } \\
\hline Sample & $\begin{array}{c}\mathrm{O} 1 \mathrm{~s}_{(\mathrm{I})} \\
\mathrm{BE} / \text { Area * }\end{array}$ & $\begin{array}{c}\text { O 1s } \mathbf{s}_{(\mathrm{II})} \\
\text { BE / Area * }\end{array}$ & $\begin{array}{c}\text { O 1s } \mathrm{s}_{(\mathrm{III})} \\
\text { BE / Area * }\end{array}$ \\
\hline Zn_Nit & $530.0 \mathrm{eV} / 33.9 \%$ & $531.5 \mathrm{eV} / 66.1 \%$ & - \\
\hline Zn_Ace & $529.2 \mathrm{eV} / 24.8 \%$ & $531.5 \mathrm{eV} / 75.2 \%$ & - \\
\hline Zn_Sul & $529.2 \mathrm{eV} / 1.2 \%$ & $531.3 \mathrm{eV} / 84.5 \%$ & $532.3 \mathrm{eV} / 14.3 \%$ \\
\hline
\end{tabular}

*Relative area

\subsection{Photoluminescence (PL) spectroscopy}

The PL spectroscopy was considered an effective method to study the optical properties and structural defects [ref], which can be applied to understand the photocatalytic performance of studied samples. Fig. 5 shows the room-temperature PL spectra of the Zn_Nit, Zn_Ace, and Zn_Sul samples. The spectra exhibited similar profile, typical of $\mathrm{ZnO}$ compound, with a narrow ultraviolet (UV) emission peak at approximately $390 \mathrm{~nm}$, and a broadband visible emission ranging from 450 to $800 \mathrm{~nm}$. [95-99] According to literature, the UV emission corresponds to a near band edge (NBE) transition, which is related to excitonic recombination caused by shallow donors inside the ZnO band-gap. [96,100-102] The visible emission has been attributed to the presence intrinsic and extrinsic defects, and also adsorbed molecules on the $\mathrm{ZnO}$ surface. [98,101,103-106] Some researchers have related the visible emission of ZnO 
compound to oxygen-related defects, such as oxygen vacancies. [98,101,103-106] Also, the PL emission in this region has been used as a direct measure of the surface defect of $\mathrm{ZnO}$ crystals.[101,102]

As shown in the inset of Fig.5, the intensity of UV emission is quite similar in all samples, suggesting that the recombination of photogenerated carriers was not affected by the choice of the $\mathrm{Zn}$ source. Unlikely, the intensity of visible emission showed a strong dependence on the $\mathrm{Zn}$ source, the observed order was $\mathrm{ZnNit}>\mathrm{Zn}$ _Ace $>\mathrm{Zn}$ _Sul. Usually, $\mathrm{ZnO}$ compound prepared via chemical routes exhibits a strongly emission in the visible region, related to the surface oxygen defects and also hydroxyl $(\mathrm{OH})$ groups adsorbed on crystal surface.[17,77,100,107] These findings indicated that intense visible emission of $\mathrm{Zn} \_$Nit sample can be attributed to the related to a high concentration of surface defects, mainly oxygen vacancies, and the presence of $\mathrm{OH}$ groups previously identified by XPS analysis. Thus, the presence of such defects and the adsorbed species are responsible to the best photocatalytic performance of Zn_Nit sample, since they act as active sites for redox reactions. $[17,77,92,108]$

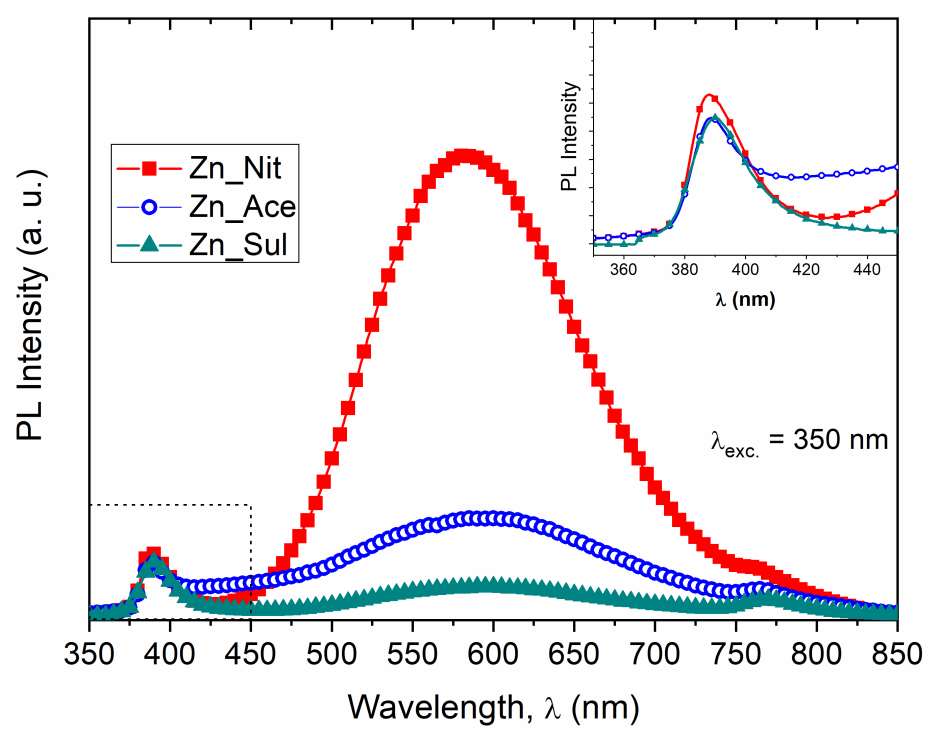


Figure 5 - Room temperature photoluminescence spectra of the Zn_Nit, Zn_Ace, and Zn_Sul samples. The inset shows the near band-edge region of the PL spectra.

\subsection{Theoretical approaches}

Over the past years, some studies have demonstrated the relationship between crystal facets and catalytic activity and how the photocatalytic activity is enhanced by exposing their most active facets $[29,46,48,109]$. In one of these studies, Boppella and co-workers [48] reported that such enhancement is a result of a greater fraction of exposed polar surfaces of $\mathrm{ZnO}$ obtained by hydrothermal treatment [50]. In a similar study, Chen and co-workers observed that exposed facets are more important to guarantee the stability of the $\mathrm{ZnO}$ photocatalyst than the crystal size [110]. Based on these investigations, we imposed a surface energy modulation in order to get insights into the growth of $\mathrm{ZnO}$ crystals and the relationship between crystal surfaces and photocatalytic activity. This strategy was used to create routes containing the path of morphological changes between the observed particles according to the Wulff construction, as it can be seen in our previous studies [58-60,111]. In this sense, we based our work on the surface energies obtained by Na and Park [63], who modeled the 100, 110 and 001 surfaces, similar to what we did with some of the same exposed surfaces of our particles. Therefore, the ideal morphology using the Wulff construction method in vacuum condition was generated according to the estimated surface energies, as illustrated in Fig. 6(a). 
a)

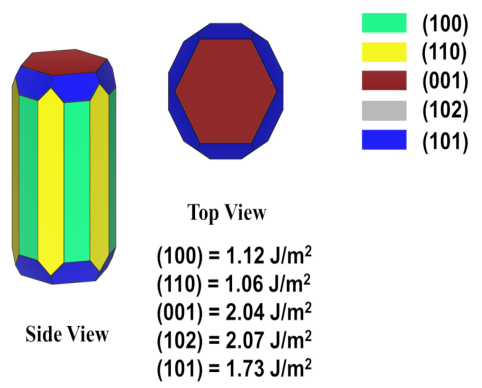

c) b)

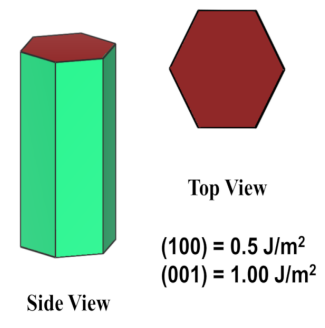

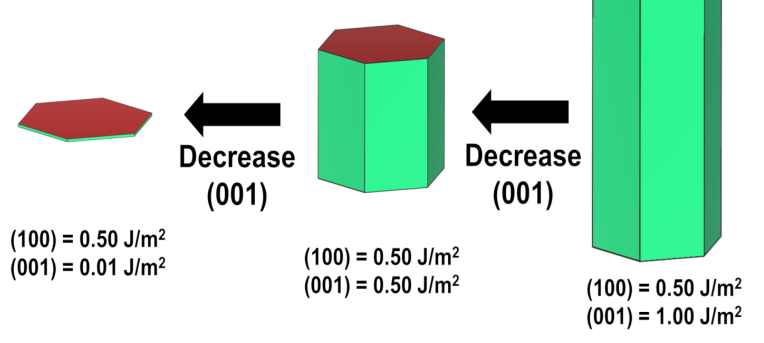

Figure 6- (a)-(c) Different morphologies of $\mathrm{ZnO}$ crystals based on the Wullf construction obtained by varying the values of surface energies of the exposed surfaces.

Even though the 100 and 110 surfaces are theoretically estimated to have similar characteristics (energy, polarity and structure) $[63,112,113]$, it is usually described that the 100 surface is the exposed surface in the rod morphologies [18,114-116]. Furthermore, the 101 surface can also be seen in some experimental particles with exposure rates highly dependent on the synthesis method, demonstrating that the stability of such surface is easily modified $[18,74,117]$. In the case of the 001 surface, there is a discrepancy between theoretical studies on its energy, showing that such surface represents a more complicated structure to be evaluated. However, it is common sense that it should be treated as a polar surface $[63,112,113]$. 
It is worth mentioning that the particles in our study did not show such variety of surfaces, as observed in Fig. 6. The synthesis methods used resulted only in morphologies with a combination of 100 and 001 surfaces, as previously presented in Fig. 2. A similar shape of the experimental morphology could be obtained by imposing a stabilization of these two surfaces, as it can be seen in Fig. 6(b). Nevertheless, this rod did not remain constant with the modification of the counter-ions present in the environment. The response of different 100/001 energy rates in the morphology rates is shown in Fig. 6(c). According to the estimative of the surface energy in the figure, the $\mathrm{SO}_{4}{ }^{2-}$ anion caused a great stabilization of the 001 surface, making it about 1000 times more stable than the 100 surface. This passivation did not allow the particle growth in the [001] direction, resulting in agglomerated plates.

It is evident the importance of counter-ions on the crystal growth mechanism of $\mathrm{ZnO}$ crystals via hydrothermal treatment, since they affect the formation process of $\left[\mathrm{ZnO}_{4}\right]$ clusters in the $\mathrm{ZnO}$ network [31]. The characteristics of the environment, sulfide ions in this case, can drastically alter the surface properties, and consequently the morphologies in the equilibrium condition [118].

Regarding the relationship between crystal shape and photoactivity, the hexagonal plate-like structures of the Zn_Sul sample should favor the photocatalytic activity due to the active (001) exposed facets. According to Chen and co-workers, Zn(II) ions on the (001) facets have more ability to chemisorb oxygen species. As a result, crystals exhibiting a high percentage of (001) facets tend to exhibit a better photocatalytic performance. Nevertheless, the spurious phase observed in the Zn_Sul sample impaired its photocatalytic activity. In the case of the Zn_Nit and Zn_Ace samples, which exhibited similar morphologies, the better performance of Zn_Nit could be linked to the lower presence of impurities on the sample surface as well as the smaller diameter of 
the nanorods, which is twice smaller than that of Zn_Ace. According to XPS analyses, $\mathrm{Zn}$ _Ace presented a high amount of carbon element compared to the $\mathrm{Zn}$ Nit, as observed in Table S1. In addition, PL measurements revealed a higher concentration of inherent surface defects in Zn_Nit compared to other samples. According to Güder and co-workers, such defects are contained mainly in polar surfaces of $\mathrm{ZnO}$ crystals. [101] Therefore, the abundance of carboxylate groups and organic residuals poisoned the surface of the $\mathrm{Zn}$ _Ace sample and the low amount of surface defects, impairing the reactivity of the most stable $\mathrm{ZnO}$ surface.

Earlier reports proposed that residual organics from precursors and/or surfactant incorporated on the surface of the materials could poison the surface-active sites, thereby decreasing the catalyst performance $[23,119,120]$. Giraldi and co-workers, who prepared $\mathrm{ZnO}$ nanoparticles via chemical method and thermally treated them at various temperatures, demonstrated that the presence of carboxylate groups provided by the organic precursor (i.e. $\mathrm{Zn}$ acetate) became more relevant to the photoactivity than the specific surface area of the samples [23].

\section{Conclusions}

In summary, $\mathrm{ZnO}$ crystals were grown directly onto substrates using different $\mathrm{Zn}$ precursors (nitrate, acetate and, sulfate) via conventional hydrothermal treatment at relatively low temperature. XRD, FE-SEM, XPS, and PL measurements revealed the significant role of counter-ions in the microstructural and surface features, allowing the control over $\mathrm{ZnO}$ properties. Furthermore, the investigation on the photooxidation process showed that the $\mathrm{ZnO}$ crystals degraded both organic dyes, being the highest photoactivity observed for the sample synthesized from $\mathrm{Zn}$ nitrate. Computational simulations demonstrated that the (001) facets are more benefited by photocatalysis 
process, however, the presence of counter-ions anchored on the $\mathrm{ZnO}$ facets and also a low amount of surface defects affected the surface charges and consequently the photocatalytic performance. These findings confirm the important role played by electronic and structural characteristics of $\mathrm{ZnO}$ nanostructures in the photoactivity of such crystals and demonstrate that the presence of counter-ions on the photocatalyst surface are also key factors for understanding the photocatalytic properties of the $\mathrm{ZnO}$ compound.

\section{Acknowledgments}

The authors would like to thank Prof. Máximo Siu Li for photoluminescence (PL) spectroscopy measurements. The authors are grateful for the financial support from the Brazilian research funding institutions CNPq (grants No. 405140/2018-5, 426511/20182,311463/2017-7 and 432242/2018-0) and FAPESP (grants No. 2018/18208-0, 2017/12437-5, 2013/07296-2, 2012/15170-6 and 2013/13888-0). This study was partly financed by the Coordination for the Improvement of Higher Education Personnel (CAPES), Finance Code 001. The XPS characterizations were performed at the Brazilian Nanotechnology National Laboratory, LNNano, (Project XPS-18304), Campinas, SP, Brazil. J.A. acknowledges Ministerio de Ciencia, Innovación y Universidades (Spain), project PGC2018-094417-B-I00 and Universitat Jaume I for project UJI-B2019-30, for financially supporting this research. 
[1] S. Sharma, S. Basu, Highly reusable visible light active hierarchical porous WO3/SiO2 monolith in centimeter length scale for enhanced photocatalytic degradation of toxic pollutants, Sep. Purif. Technol. 231 (2020). https://doi.org/10.1016/j.seppur.2019.115916.

[2] J. Wen, J. Xie, X. Chen, X. Li, A review on g-C3N4-based photocatalysts, Appl. Surf. Sci. 391 (2017) 72-123. https://doi.org/https://doi.org/10.1016/j.apsusc.2016.07.030.

[3] N. Serpone, a. V. Emeline, Semiconductor Photocatalysis - Past, Present, and Future Outlook, J. Phys. Chem. Lett. 3 (2012) 673-677. https://doi.org/10.1021/jz300071j.

[4] M.R. Hoffmann, S.T. Martin, W. Choi, D.W. Bahnemann, Environmental applications of semiconductor photocatalysis, Chem. Rev. 95 (1995) 69-96. http://pubs.acs.org/doi/abs/10.1021/cr00033a004 (accessed March 2, 2013).

[5] L. Jing, W. Zhou, G. Tian, H. Fu, Surface tuning for oxide-based nanomaterials as efficient photocatalysts, Chem. Soc. Rev. 42 (2013) 9509-9549. https://doi.org/10.1039/C3CS60176E.

[6] X. Zhou, S. Lee, Z. Xu, J. Yoon, Recent Progress on the Development of Chemosensors for Gases, Chem. Rev. 115 (2015) 7944-8000. https://doi.org/10.1021/cr500567r.

[7] A. V Nikam, B.L. V Prasad, A.A. Kulkarni, Wet chemical synthesis of metal oxide nanoparticles: a review, CrystEngComm. 20 (2018) 5091-5107. https://doi.org/10.1039/C8CE00487K.

[8] E. Mirzadeh, K. Akhbari, Synthesis of nanomaterials with desirable morphologies from metal-organic frameworks for various applications, CrystEngComm. 18 (2016) 7410-7424. https://doi.org/10.1039/C6CE01076H.

[9] S. Dong, J. Feng, M. Fan, Y. Pi, L. Hu, X. Han, M. Liu, J. Sun, J. Sun, Recent developments in heterogeneous photocatalytic water treatment using visible 
light-responsive photocatalysts: a review, RSC Adv. 5 (2015) 14610-14630. https://doi.org/10.1039/C4RA13734E.

[10] A.O. Ibhadon, P. Fitzpatrick, Heterogeneous Photocatalysis: Recent Advances and Applications, CATALYSTS. 3 (2013) 189-218. https://doi.org/10.3390/catal3010189.

[11] M.I. Litter, Heterogeneous photocatalysis: Transition metal ions in photocatalytic systems, Appl. Catal. B Environ. 23 (1999) 89-114. https://doi.org/https://doi.org/10.1016/S0926-3373(99)00069-7.

[12] O. Baghriche, S. Rtimi, C. Pulgarin, J. Kiwi, Polystyrene $\mathrm{CuO} / \mathrm{Cu} 2 \mathrm{O}$ uniform films inducing MB-degradation under sunlight, Catal. Today. 284 (2017) 77-83. https://doi.org/https://doi.org/10.1016/j.cattod.2016.10.018.

[13] H. Dong, G. Zeng, L. Tang, C. Fan, C. Zhang, X. He, Y. He, An overview on limitations of $\mathrm{TiO} 2$-based particles for photocatalytic degradation of organic pollutants and the corresponding countermeasures, Water Res. 79 (2015) 128-146. https://doi.org/https://doi.org/10.1016/j.watres.2015.04.038.

[14] A.M. Ali, E.A.C. Emanuelsson, D.A. Patterson, Photocatalysis with nanostructured zinc oxide thin films: The relationship between morphology and photocatalytic activity under oxygen limited and oxygen rich conditions and evidence for a Mars Van Krevelen mechanism, Appl. Catal. BENVIRONMENTAL. 97 (2010) 168-181. https://doi.org/10.1016/j.apcatb.2010.03.037.

[15] K.T.G. Carvalho, S.C. Fidelis, O.F. Lopes, C. Ribeiro, Effect of processing variables on the photocatalytic properties of $\mathrm{ZnO}$ thin films prepared using the polymeric precursor method, Ceram. Int. 41 (2015) 10587-10594. https://doi.org/10.1016/j.ceramint.2015.04.155.

[16] R. Ahumada-Lazo, L.M. Torres-Martínez, M.A. Ruíz-Gómez, O.E. VegaBecerra, M.Z. Figueroa-Torres, Photocatalytic efficiency of reusable $\mathrm{ZnO}$ thin films deposited by sputtering technique, Appl. Surf. Sci. 322 (2014) 35-40. https://doi.org/https://doi.org/10.1016/j.apsusc.2014.10.049.

[17] L.F. Da Silva, O.F. Lopes, A.C. Catto, W. Avansi, M.I.B. Bernardi, M.S. Li, C. Ribeiro, E. Longo, Hierarchical growth of $\mathrm{ZnO}$ nanorods over $\mathrm{SnO} 2$ seed layer: insights into electronic properties from photocatalytic activity, RSC Adv. 6 (2016) 2112-2118. https://doi.org/10.1039/C5RA23824B. 
[18] G. Byzynski, C. Melo, D.P. Volanti, M.M. Ferrer, A.F. Gouveia, C. Ribeiro, J. Andres, E. Longo, The interplay between morphology and photocatalytic activity in $\mathrm{ZnO}$ and N-doped ZnO crystals, Mater. Des. 120 (2017) 363-375.

https://doi.org/10.1016/j.matdes.2017.02.020.

[19] T.S. Tofa, K.L. Kunjali, S. Paul, J. Dutta, Visible light photocatalytic degradation of microplastic residues with zinc oxide nanorods, Environ. Chem. Lett. 17 (2019) 1341-1346. https://doi.org/10.1007/s10311-019-00859-z.

[20] Y. V Kaneti, Z. Zhang, J. Yue, Q.M.D. Zakaria, C. Chen, X. Jiang, A. Yu, Crystal plane-dependent gas-sensing properties of zinc oxide nanostructures: experimental and theoretical studies, Phys. Chem. Chem. Phys. 16 (2014) 11471-11480. https://doi.org/10.1039/C4CP01279H.

[21] H.-J. Kim, J.-H. Lee, Highly sensitive and selective gas sensors using p-type oxide semiconductors: Overview, Sensors Actuators B Chem. 192 (2014) 607-627. https://doi.org/http://dx.doi.org/10.1016/j.snb.2013.11.005.

[22] T.M. Milao, V.R. de Mendonça, V.D. Araújo, W. Avansi, C. Ribeiro, E. Longo, M.I. Bernardi, Microwave Hydrothermal Synthesis and Photocatalytic Performance of $\mathrm{ZnO}$ and $<\mathrm{I}>\mathrm{M}</ \mathrm{I}>$ : $\mathrm{ZnO}$ Nanostructures $(<\mathrm{I}>\mathrm{M}</ \mathrm{I}>=\mathrm{V}, \mathrm{Fe}$, Co), Sci. Adv. Mater. 4 (2012) 54-60. https://doi.org/10.1166/sam.2012.1251.

[23] T.R. Giraldi, G.V.F. Santos, V.R. Mendonça, C. Ribeiro, I.T. Weber, Annealing Effects on the Photocatalytic Activity of ZnO Nanoparticles, J. Nanosci. Nanotechnol. 11 (n.d.) 3635-3640.

[24] D. Li, H. Haneda, Morphologies of zinc oxide particles and their effects on photocatalysis, Chemosphere. 51 (2003) 129-137. https://doi.org/10.1016/S00456535(02)00787-7.

[25] K.P. Wai, Y.L. Pang, S. Lim, C.H. Koo, W.C. Chong, Hydrothermal modification of zinc oxide and titanium dioxide for photocatalytic degradation of Rhodamine B, AIP Conf. Proc. 2157 (2019) 20006. https://doi.org/10.1063/1.5126541.

[26] T. Khalafi, F. Buazar, K. Ghanemi, Phycosynthesis and Enhanced Photocatalytic Activity of Zinc Oxide Nanoparticles Toward Organosulfur Pollutants, Sci. Rep. 9 (2019) 6866. https://doi.org/10.1038/s41598-019-43368-3.

[27] A.M. Tayeb, M.A. Tony, E.K. Ismaeel, Engineered nanostructured $\mathrm{ZnO}$ for water remediation: operational parameters effect, Box-Behnken design optimization 
and kinetic determinations, Appl. Water Sci. 9 (2019) 43.

https://doi.org/10.1007/s13201-019-0921-0.

[28] G.T.S.T. da Silva, K.T.G. Carvalho, O.F. Lopes, E.S. Gomes, A.R. Malagutti, V.R. Mastelaro, C. Ribeiro, H.A.J.L. Mourao, Synthesis of ZnO Nanoparticles Assisted by N Sources and their Application in the Photodegradation of Organic Contaminants, ChemCatChem. 9 (2017) 3795-3804. https://doi.org/10.1002/cctc.201700756.

[29] S. Vallejos, N. Pizúrová, I. Gràcia, C. Sotelo-Vazquez, J. Čechal, C. Blackman, I. Parkin, C. Cané, ZnO Rods with Exposed $\{100\}$ Facets Grown via a SelfCatalyzed Vapor-Solid Mechanism and Their Photocatalytic and Gas Sensing Properties, ACS Appl. Mater. Interfaces. 8 (2016) 33335-33342. https://doi.org/10.1021/acsami.6b12992.

[30] M.A. Mahmood, S. Jan, I.A. Shah, I. Khan, Growth Parameters for Films of Hydrothermally Synthesized One-Dimensional Nanocrystals of Zinc Oxide, Int. J. Photoenergy. 2016 (2016) 3153170. https://doi.org/10.1155/2016/3153170.

[31] A.C. Catto, L.F. da Silva, C. Ribeiro, S. Bernardini, K. Aguir, E. Longo, V.R. Mastelaro, An easy method of preparing ozone gas sensors based on $\mathrm{ZnO}$ nanorods, RSC Adv. 5 (2015) 19528-19533. https://doi.org/10.1039/C5RA00581G.

[32] N. Joshi, L.F. da Silva, F.M. Shimizu, V.R. Mastelaro, J.-C. M'Peko, L. Lin, O.N. Oliveira, UV-assisted chemiresistors made with gold-modified $\mathrm{ZnO}$ nanorods to detect ozone gas at room temperature, Microchim. Acta. 186 (2019) 418. https://doi.org/10.1007/s00604-019-3532-4.

[33] R.S. Kammel, R.S. Sabry, Effects of the aspect ratio of $\mathrm{ZnO}$ nanorods on the performance of piezoelectric nanogenerators, J. Sci. Adv. Mater. Devices. 4 (2019) 420-424. https://doi.org/https://doi.org/10.1016/j.jsamd.2019.08.002.

[34] S. Heinonen, J.-P. Nikkanen, H. Hakola, E. Huttunen-Saarivirta, M. Kannisto, L. Hyvärinen, M. Järveläinen, E. Levänen, Effect of temperature and concentration of precursors on morphology and photocatalytic activity of zinc oxide thin films prepared by hydrothermal route, \{IOP $\}$ Conf. Ser. Mater. Sci. Eng. 123 (2016) 12030. https://doi.org/10.1088/1757-899x/123/1/012030.

[35] N.A. Alshehri, A.R. Lewis, C. Pleydell-Pearce, T.G.G. Maffeis, Investigation of the growth parameters of hydrothermal $\mathrm{ZnO}$ nanowires for scale up applications, 
J. Saudi Chem. Soc. 22 (2018) 538-545.

https://doi.org/https://doi.org/10.1016/j.jscs.2017.09.004.

[36] A. Jaggessar, T. Tesfamicheal, H. Wang, C. Yan, P.K.D. V Yarlagadda, Investigation of mechanical properties and morphology of hydrothermally manufactured titanium dioxide nanostructured surfaces, Procedia Manuf. 30 (2019) 373-379. https://doi.org/https://doi.org/10.1016/j.promfg.2019.02.052.

[37] L. Wang, G. Liu, L. Zou, D. Xue, Phase evolution from rod-like ZnO to platelike zinc hydroxysulfate during electrochemical deposition, J. Alloys Compd. 493 (2010) 471-475.

https://doi.org/https://doi.org/10.1016/j.jallcom.2009.12.129.

[38] U. Pal, P. Santiago, Controlling the Morphology of ZnO Nanostructures in a Low-Temperature Hydrothermal Process, J. Phys. Chem. B. 109 (2005) 15317-15321. https://doi.org/10.1021/jp052496i.

[39] W. Avansi, C.L.P. Oliveira, C. Ribeiro, E.R. Leite, V.R. Mastelaro, Study of the morphological evolution of vanadium pentoxide nanostructures under hydrothermal conditions, CrystEngComm. 18 (2016) 7636-7641. https://doi.org/10.1039/C6CE01196A.

[40] A. Gurlo, Nanosensors: Does Crystal Shape Matter?, Small. 6 (2010) 2077-2079. https://doi.org/10.1002/smll.201000680.

[41] G. Liu, J.C. Yu, G.Q. (Max) Lu, H.-M. Cheng, Crystal facet engineering of semiconductor photocatalysts: motivations $\{$,$\} advances and unique properties,$ Chem. Commun. 47 (2011) 6763-6783. https://doi.org/10.1039/C1CC10665A.

[42] R. Singh, K. Verma, A. Patyal, I. Sharma, P.B. Barman, D. Sharma, Nanosheet and nanosphere morphology dominated photocatalytic \& antibacterial properties of $\mathrm{ZnO}$ nanostructures, Solid State Sci. 89 (2019) 1-14. https://doi.org/https://doi.org/10.1016/j.solidstatesciences.2018.12.011.

[43] K. Kaviyarasu, C. Maria Magdalane, K. Kanimozhi, J. Kennedy, B. Siddhardha, E. Subba Reddy, N.K. Rotte, C.S. Sharma, F.T. Thema, D. Letsholathebe, G.T. Mola, M. Maaza, Elucidation of photocatalysis, photoluminescence and antibacterial studies of $\mathrm{ZnO}$ thin films by spin coating method, J. Photochem. Photobiol. B Biol. 173 (2017) 466-475. https://doi.org/https://doi.org/10.1016/j.jphotobiol.2017.06.026.

[44] E. Debroye, J. Van Loon, H. Yuan, K.P.F. Janssen, Z. Lou, S. Kim, T. Majima, 
M.B.J. Roeffaers, Facet-Dependent Photoreduction on Single ZnO Crystals, J. Phys. Chem. Lett. 8 (2017) 340-346. https://doi.org/10.1021/acs.jpclett.6b02577.

[45] L. Roza, V. Fauzia, M.Y.A. Rahman, Tailoring the active surface sites of ZnO nanorods on the glass substrate for photocatalytic activity enhancement, Surfaces and Interfaces. 15 (2019) 117-124. https://doi.org/https://doi.org/10.1016/j.surfin.2019.02.009.

[46] Y.-K. Peng, S.C.E. Tsang, Facet-dependent photocatalysis of nanosize semiconductive metal oxides and progress of their characterization, Nano Today. 18 (2018) 15-34. https://doi.org/10.1016/j.nantod.2017.12.011.

[47] A. Mclaren, T. Valdes-Solis, G. Li, S.C. Tsang, Shape and Size Effects of ZnO Nanocrystals on Photocatalytic Activity, J. Am. Chem. Soc. 131 (2009) 12540-12541. https://doi.org/10.1021/ja9052703.

[48] R. Boppella, K. Anjaneyulu, P. Basak, S. V Manorama, Facile Synthesis of Face Oriented ZnO Crystals: Tunable Polar Facets and Shape Induced Enhanced Photocatalytic Performance, J. Phys. Chem. C. 117 (2013) 4597-4605. https://doi.org/10.1021/jp311443s.

[49] F. Haque, S. Chenot, F. Viñes, F. Illas, S. Stankic, J. Jupille, ZnO powders as multi-facet single crystals, Phys. Chem. Chem. Phys. 19 (2017) 10622-10628. https://doi.org/10.1039/C7CP01635B.

[50] S. He, S. Zhang, J. Lu, Y. Zhao, J. Ma, M. Wei, D.G. Evans, X. Duan, Enhancement of visible light photocatalysis by grafting $\mathrm{ZnO}$ nanoplatelets with exposed (0001) facets onto a hierarchical substrate, Chem. Commun. 47 (2011) 10797-10799. https://doi.org/10.1039/C1CC14360C.

[51] A. Iglesias-Juez, F. Viñes, O. Lamiel-García, M. Fernández-García, F. Illas, Morphology effects in photoactive $\mathrm{ZnO}$ nanostructures: photooxidative activity of polar surfaces, J. Mater. Chem. A. 3 (2015) 8782-8792. https://doi.org/10.1039/C5TA01111F.

[52] L. Xu, Y.-L. Hu, C. Pelligra, C.-H. Chen, L. Jin, H. Huang, S. Sithambaram, M. Aindow, R. Joesten, S.L. Suib, ZnO with Different Morphologies Synthesized by Solvothermal Methods for Enhanced Photocatalytic Activity, Chem. Mater. 21 (2009) 2875-2885. https://doi.org/10.1021/cm900608d.

[53] S.G. Kumar, K.S.R.K. Rao, Zinc oxide based photocatalysis: tailoring surfacebulk structure and related interfacial charge carrier dynamics for better 
environmental applications, RSC Adv. 5 (2014) 3306-3351.

https://doi.org/10.1039/C4RA13299H.

[54] X. Liu, L. Ye, S. Liu, Y. Li, X. Ji, Photocatalytic Reduction of CO2 by ZnO Micro/nanomaterials with Different Morphologies and Ratios of $\{0001\}$ Facets, Sci. Rep. 6 (2016) 38474. https://doi.org/10.1038/srep38474.

[55] F. Labat, I. Ciofini, C. Adamo, Modeling ZnO phases using a periodic approach: From bulk to surface and beyond, J. Chem. Phys. 131 (2009) 44708. https://doi.org/10.1063/1.3179752.

[56] W. Yu, J. Zhang, T. Peng, New insight into the enhanced photocatalytic activity of N-, C- and S-doped ZnO photocatalysts, Appl. Catal. B Environ. 181 (2016) 220-227. https://doi.org/https://doi.org/10.1016/j.apcatb.2015.07.031.

[57] J. Andrés, L. Gracia, A.F. Gouveia, M.M. Ferrer, E. Longo, Effects of surface stability on the morphological transformation of metals and metal oxides as investigated by first-principles calculations, Nanotechnology. 26 (2015) 405703.

[58] M.M.F. and A.F.G. and L.G. and E.L. and J. Andrés, A 3D platform for the morphology modulation of materials: first principles calculations on the thermodynamic stability and surface structure of metal oxides: Co $3 \mathrm{O} 4, \alpha$-Fe 2 O 3 , and In 2 O 3, Model. Simul. Mater. Sci. Eng. 24 (2016) 25007.

[59] M. de A. Barbosa, G. da S.L. Fabris, M.M. Ferrer, D.H.M. de Azevedo, J.R. Sambrano, Computational Simulations of Morphological Transformations by Surface Structures: The Case of Rutile TiO2 phase, Mater. Res. 20 (2017) $920-925$.

[60] M.M. Ferrer, G.S.L. Fabris, B. V de Faria, J.B.L. Martins, M.L. Moreira, J.R. Sambrano, Quantitative evaluation of the surface stability and morphological changes of $\mathrm{Cu} 2 \mathrm{O}$ particles, Heliyon. 5 (2019) e02500. https://doi.org/https://doi.org/10.1016/j.heliyon.2019.e02500.

[61] XXV. Zur Frage der Geschwindigkeit des Wachsthums und der Auflösung der Krystallflächen , Zeitschrift Für Krist. - Cryst. Mater. . 34 (1901) 449. https://doi.org/10.1524/zkri.1901.34.1.449.

[62] V.R. de Mendonça, H.A.J.L. Mourão, A.R. Malagutti, C. Ribeiro, The role of the relative dye/photocatalyst concentration in TiO 2 assisted photodegradation process, Photochem. Photobiol. 90 (2014) 66-72. https://doi.org/10.1111/php.12175. 
[63] S. Na, C. Park, P. Chul-Hong, First-Principles Study of the Surface Energy and Atom Cohesion of Wurtzite $\mathrm{ZnO}$ and $\mathrm{ZnS}$ - Implications for Nanostructure Formation, J. Korean Phys. Soc. 56 (2010) 498. https://doi.org/10.3938/jkps.56.498.

[64] G. Kresse, D. Joubert, From ultrasoft pseudopotentials to the projector augmented-wave method, Phys. Rev. B. 59 (1999) 1758-1775. https://doi.org/10.1103/PhysRevB.59.1758.

[65] A.A.G. Santiago, R.L. Tranquilin, M.C. Oliveira, R.A.P. Ribeiro, S.R. de Lazaro, M.A. Correa, F. Bohn, E. Longo, F. V Motta, M.R.D. Bomio, Disclosing the Structural, Electronic, Magnetic, and Morphological Properties of CuMnO2: A Unified Experimental and Theoretical Approach, J. Phys. Chem. C. 124 (2020) 5378-5388. https://doi.org/10.1021/acs.jpcc.0c00198.

[66] A.F. Gouveia, M. Assis, L.S. Cavalcante, L. Gracia, E. Longo, J. Andrés, Reading at exposed surfaces: theoretical insights into photocatalytic activity of ZnWO4 ， Front. Res. Today . 1 (2018) 1005. https://doi.org/10.31716/frt.201801005 .

[67] K. Momma, F. Izumi, VESTA 3 for three-dimensional visualization of crystal, volumetric and morphology data, J. Appl. Crystallogr. 44 (2011) 1272-1276. https://doi.org/10.1107/S0021889811038970.

[68] A.C. Catto, L.F. Da Silva, C. Ribeiro, S. Bernardini, K. Aguir, E. Longo, V.R. Mastelaro, An easy method of preparing ozone gas sensors based on $\mathrm{ZnO}$ nanorods, RSC Adv. 5 (2015). https://doi.org/10.1039/c5ra00581g.

[69] J. Song, S. Lim, Effect of seed layer on the growth of $\mathrm{ZnO}$ nanorods, J. Phys. Chem. C. 111 (2007) 596-600. https://doi.org/10.1021/jp0655017.

[70] R.M. Dziedzic, A.L. Gillian-Daniel, G.M. Petersen, K.J. Martínez-Hernández, Microwave Synthesis of Zinc Hydroxy Sulfate Nanoplates and Zinc Oxide Nanorods in the Classroom, J. Chem. Educ. 91 (2014) 1710-1714. https://doi.org/10.1021/ed400669v.

[71] A. Moezzi, M.B. Cortie, A.M. McDonagh, Zinc hydroxide sulphate and its transformation to crystalline zinc oxide, Dalt. Trans. 42 (2013) 14432-14437. https://doi.org/10.1039/C3DT51638E.

[72] X. Yan, Z. Li, R. Chen, W. Gao, Template Growth of ZnO Nanorods and Microrods with Controllable Densities, Cryst. Growth Des. 8 (2008) 2406-2410. 
https://doi.org/10.1021/cg7012599.

[73] X. Li, J. Wang, J. Yang, J. Lang, S. Lü, M. Wei, X. Meng, C. Kou, X. Li, Comparison of photocatalytic activity of $\mathrm{ZnO}$ rod arrays with various diameter sizes and orientation, J. Alloys Compd. 580 (2013) 205-210. https://doi.org/https://doi.org/10.1016/j.jallcom.2013.05.037.

[74] X. Cai, B. Han, S. Deng, Y. Wang, C. Dong, Y. Wang, I. Djerdj, Hydrothermal growth of $\mathrm{ZnO}$ nanorods on $\mathrm{Zn}$ substrates and their application in degradation of azo dyes under ambient conditions, CrystEngComm. 16 (2014) 7761-7770. https://doi.org/10.1039/C4CE00899E.

[75] Q. Yu, L. Li, H. Li, S. Gao, D. Sang, J. Yuan, P. Zhu, Synthesis and properties of boron doped $\mathrm{ZnO}$ nanorods on silicon substrate by low-temperature hydrothermal reaction, Appl. Surf. Sci. 257 (2011) 5984-5988. https://doi.org/https://doi.org/10.1016/j.apsusc.2011.01.081.

[76] R. Yi, H. Zhou, N. Zhang, G. Qiu, X. Liu, Effects of specific salts on the morphologies of ZnO microstructures, J. Alloys Compd. 479 (2009) L50-L53. https://doi.org/https://doi.org/10.1016/j.jallcom.2009.01.048.

[77] M.R. Alenezi, S.J. Henley, N.G. Emerson, S.R.P. Silva, From 1D and 2D ZnO nanostructures to $3 \mathrm{D}$ hierarchical structures with enhanced gas sensing properties, Nanoscale. 6 (2014) 235-247. https://doi.org/10.1039/c3nr04519f.

[78] K.T.G. Carvalho, O.F. Lopes, D.C. Ferreira, C. Ribeiro, ZnO:ZnWO4 heterostructure with enhanced photocatalytic activity for pollutant degradation in liquid and gas phases, J. Alloys Compd. 797 (2019) 1299-1309. https://doi.org/10.1016/j.jallcom.2019.05.144.

[79] L.F. Da Silva, O.F. Lopes, V.R. De Mendon??a, K.T.G. Carvalho, E. Longo, C. Ribeiro, V.R. Mastelaro, An Understanding of the Photocatalytic Properties and Pollutant Degradation Mechanism of SrTiO3 Nanoparticles, Photochem. Photobiol. (2016). https://doi.org/10.1111/php.12586.

[80] K. Ishibashi, A. Fujishima, Quantum yields of active oxidative species formed on TiO 2 photocatalyst, J. Photochem. Photobiol. A Chem. 134 (2000) 139-142. http://www.sciencedirect.com/science/article/pii/S1010603000002641 (accessed March 2, 2013).

[81] Y. Mao, C. Schoeneich, K. Asmus, intermediates in oxidative degradation of chlorinated ethanes on titania surfaces en route to mineralization: a combined 
photocatalytic and radiation chemical study, J. Phys. Chem. 95 (1991)

10080-10089. http://pubs.acs.org/doi/abs/10.1021/j100177a085 (accessed March 2, 2013).

[82] M. Aslam, I.M.I. Ismail, S. Chandrasekaran, H.A. Qari, A. Hameed, How the dyes are degraded/mineralized in a photocatalytic system? the possible role of auxochromes, Water. Air. Soil Pollut. 226 (2015). https://doi.org/10.1007/s11270-015-2301-1.

[83] N. Salah, A. Hameed, M. Aslam, M.S. Abdel-wahab, S.S. Babkair, F.S. Bahabri, Flow controlled fabrication of $\mathrm{N}$ doped $\mathrm{ZnO}$ thin films and estimation of their performance for sunlight photocatalytic decontamination of water, Chem. Eng. J. 291 (2016) 115-127. https://doi.org/10.1016/j.cej.2016.01.111.

[84] M.T. Qamar, M. Aslam, Z.A. Rehan, M.T. Soomro, J.M. Basahi, I.M.I. Ismail, T. Almeelbi, A. Hameed, The influence of p-type Mn3O4 nanostructures on the photocatalytic activity of $\mathrm{ZnO}$ for the removal of bromo and chlorophenol in natural sunlight exposure, Appl. Catal. B Environ. 201 (2017) 105-118. https://doi.org/10.1016/j.apcatb.2016.08.004.

[85] O.F. Lopes, V.R. De Mendonça, F.B.F. Silva, E.C. Paris, C. Ribeiro, Niobium oxides: An overview of the synthesis of $\mathrm{Nb}<\inf >2</ \inf >\mathrm{O}<\inf >5</ \inf >$ and its application in heterogeneous photocatalysis, Quim. Nova. 38 (2015). https://doi.org/10.5935/0100-4042.20140280.

[86] G.T.S.T. Silva, K.T.G. Carvalho, O.F. Lopes, E.S. Gomes, Synthesis of ZnO Nanoparticles Assisted by N Sources and their Application in the Photodegradation of Organic Contaminants, (2017) 3795-3804. https://doi.org/10.1002/cctc.201700756.

[87] D. Zhang, Z. Yang, P. Li, X. Zhou, Ozone gas sensing properties of metalorganic frameworks-derived $\mathrm{In} 2 \mathrm{O} 3$ hollow microtubes decorated with $\mathrm{ZnO}$ nanoparticles, Sensors Actuators B Chem. 301 (2019) 127081. https://doi.org/https://doi.org/10.1016/j.snb.2019.127081.

[88] M.T. Qamar, M. Aslam, I.M.I. Ismail, N. Salah, A. Hameed, Synthesis, characterization, and sunlight mediated photocatalytic activity of $\mathrm{CuO}$ coated $\mathrm{ZnO}$ for the removal of nitrophenols, ACS Appl. Mater. Interfaces. 7 (2015) 8757-8769. https://doi.org/10.1021/acsami.5b01273.

[89] J. Landoulsi, M.J. Genet, S. Fleith, Y. Touré, I. Liascukiene, C. Méthivier, P.G. 
Rouxhet, Organic adlayer on inorganic materials: XPS analysis selectivity to cope with adventitious contamination, Appl. Surf. Sci. 383 (2016) 71-83. https://doi.org/https://doi.org/10.1016/j.apsusc.2016.04.147.

[90] B. Huang, G. Liu, P. Wang, X. Zhao, H. Xu, Effect of Nitric Acid Modification on Characteristics and Adsorption Properties of Lignite, PROCESSES. 7 (2019). https://doi.org/10.3390/pr7030167.

[91] H. Ma, L. Yue, C. Yu, X. Dong, X. Zhang, M. Xue, X. Zhang, Y. Fu, Synthesis, characterization and photocatalytic activity of $\mathrm{Cu}$-doped $\mathrm{Zn} / \mathrm{ZnO}$ photocatalyst with carbon modification, J. Mater. Chem. 22 (2012) 23780-23788. https://doi.org/10.1039/C2JM35110B.

[92] X. Zhang, J. Qin, Y. Xue, P. Yu, B. Zhang, L. Wang, R. Liu, Effect of aspect ratio and surface defects on the photocatalytic activity of $\mathrm{ZnO}$ nanorods, Sci. Rep. 4 (2014) 4596.

[93] G. Byzynski, D.P. Volanti, C. Ribeiro, V.R. Mastelaro, E. Longo, Direct photooxidation and superoxide radical as major responsible for dye photodegradation mechanism promoted by TiO2-rGO heterostructure, J. Mater. Sci. Mater. Electron. 29 (2018) 17022-17037. https://doi.org/10.1007/s10854-018-9799-0.

[94] H. Wu, L. Xie, R. Zhang, Y. Tian, S. Liu, M. He, C. Huang, W. Tian, A novel method to fabricate organic-free superhydrophobic surface on titanium substrates by removal of surface hydroxyl groups, Appl. Surf. Sci. 479 (2019) 1089-1097. https://doi.org/https://doi.org/10.1016/j.apsusc.2019.02.162.

[95] M.E. Fragalà, A. Di Mauro, G. Litrico, F. Grassia, G. Malandrino, G. Foti, Controlled large-scale fabrication of sea sponge-like $\mathrm{ZnO}$ nanoarchitectures on textured silicon, CrystEngComm. 11 (2009) 2770-2775. https://doi.org/10.1039/B914541A.

[96] Y.-T. Tseng, J.-C. Lin, Y.-J. Ciou, Y.-R. Hwang, Fabrication of a Novel Microsensor Consisting of Electrodeposited $\mathrm{ZnO}$ Nanorod-Coated Crossed $\mathrm{Cu}$ Micropillars and the Effects of Nanorod Coating Morphology on the Gas Sensing, ACS Appl. Mater. Interfaces. 6 (2014) 11424-11438. https://doi.org/10.1021/am5019836.

[97] A.C. Catto, L.F. da Silva, M.I.B. Bernardi, M.S. Li, E. Longo, P.N. Lisboa-Filho, O.R. Nascimento, V.R. Mastelaro, An investigation into the influence of zinc precursor on the microstructural, photoluminescence, and gas-sensing properties 
of ZnO nanoparticles, J. Nanoparticle Res. 16 (2014) 1-9.

https://doi.org/10.1007/s11051-014-2760-0.

[98] N.A. Putri, V. Fauzia, S. Iwan, L. Roza, A.A. Umar, S. Budi, Mn-doping-induced photocatalytic activity enhancement of $\mathrm{ZnO}$ nanorods prepared on glass substrates, Appl. Surf. Sci. 439 (2018) 285-297. https://doi.org/https://doi.org/10.1016/j.apsusc.2017.12.246.

[99] M. Aslam, I.M.I. Ismail, T. Almeelbi, N. Salah, S. Chandrasekaran, A. Hameed, Enhanced photocatalytic activity of $\mathrm{V} 2 \mathrm{O} 5-\mathrm{ZnO}$ composites for the mineralization of nitrophenols, Chemosphere. 117 (2014) 115-123. https://doi.org/10.1016/j.chemosphere.2014.05.076.

[100] R. Amiruddin, M.C.S. Kumar, Enhanced visible emission from vertically aligned $\mathrm{ZnO}$ nanostructures by aqueous chemical growth process, J. Lumin. 155 (2014) 149-155. https://doi.org/https://doi.org/10.1016/j.jlumin.2014.06.038.

[101] F. Güder, Y. Yang, A. Menzel, C. Wang, J. Danhof, K. Subannajui, A. Hartel, D. Hiller, R. Kozhummal, N.S. Ramgir, V. Cimalla, U.T. Schwarz, M. Zacharias, Superior Functionality by Design: Selective Ozone Sensing Realized by Rationally Constructed High-Index ZnO Surfaces, Small. 8 (2012) 3307-3314. https://doi.org/10.1002/smll.201200841.

[102] A.B. Djurišić, W.C.H. Choy, V.A.L. Roy, Y.H. Leung, C.Y. Kwong, K.W. Cheah, T.K. Gundu Rao, W.K. Chan, H. Fei Lui, C. Surya, Photoluminescence and Electron Paramagnetic Resonance of ZnO Tetrapod Structures, Adv. Funct. Mater. 14 (2004) 856-864. https://doi.org/doi:10.1002/adfm.200305082.

[103] M. Wang, Y. Zhang, Y. Zhou, F. Yang, E.J. Kim, S.H. Hahn, S.G. Seong, Rapid room-temperature synthesis of nanosheet-assembled $\mathrm{ZnO}$ mesocrystals with excellent photocatalytic activity, CrystEngComm. 15 (2013) 754-763. https://doi.org/10.1039/C2CE26660A.

[104] Y. Zheng, C. Chen, Y. Zhan, X. Lin, Q. Zheng, K. Wei, J. Zhu, Y. Zhu, Luminescence and Photocatalytic Activity of $\mathrm{ZnO}$ Nanocrystals: Correlation between Structure and Property, Inorg. Chem. 46 (2007) 6675-6682. https://doi.org/10.1021/ic062394m.

[105] F. Kayaci, S. Vempati, I. Donmez, N. Biyikli, T. Uyar, Role of zinc interstitials and oxygen vacancies of $\mathrm{ZnO}$ in photocatalysis: a bottom-up approach to control defect density, Nanoscale. 6 (2014) 10224-10234. 
https://doi.org/10.1039/C4NR01887G.

[106] H.W. Jeong, S.-Y. Choi, S.H. Hong, S.K. Lim, D.S. Han, A. Abdel-Wahab, H. Park, Shape-Dependent Charge Transfers in Crystalline ZnO Photocatalysts: Rods versus Plates, J. Phys. Chem. C. 118 (2014) 21331-21338. https://doi.org/10.1021/jp506032f.

[107] N. Neykova, Y.-Y. Chang, M. Buryi, M. Davydova, R. Kucerkova, D. Simek, Z. Remes, O. Pop-Georgievski, Study of $\mathrm{ZnO}$ nanorods grown under UV irradiation, Appl. Surf. Sci. 472 (2019) 105-111. https://doi.org/https://doi.org/10.1016/j.apsusc.2018.03.173.

[108] E.A. Araújo Júnior, F.X. Nobre, G. da S. Sousa, L.S. Cavalcante, M. Rita de Morais Chaves Santos, F.L. Souza, J.M. Elias de Matos, Synthesis, growth mechanism, optical properties and catalytic activity of $\mathrm{ZnO}$ microcrystals obtained via hydrothermal processing, RSC Adv. 7 (2017) 24263-24281. https://doi.org/10.1039/C7RA03277C.

[109] L.Q. Jing, Z.L. Xu, X.J. Sun, J. Shang, W.M. Cai, The surface properties and photocatalytic activities of ZnO ultrafine particles, Appl. Surf. Sci. 180 (2001) 308-314. https://doi.org/10.1016/S0169-4332(01)00365-8.

[110] W. Chen, Q. Liu, S. Tian, X. Zhao, Exposed facet dependent stability of ZnO micro/nano crystals as a photocatalyst, Appl. Surf. Sci. 470 (2019) 807-816. https://doi.org/https://doi.org/10.1016/j.apsusc.2018.11.206.

[111] J.A. and L.G. and A.F.G. and M.M.F. and E. Longo, Effects of surface stability on the morphological transformation of metals and metal oxides as investigated by first-principles calculations, Nanotechnology. 26 (2015) 405703.

[112] H.F. Wilson, C. Tang, A.S. Barnard, Morphology of Zinc Oxide Nanoparticles and Nanowires: Role of Surface and Edge Energies, J. Phys. Chem. C. 120 (2016) 9498-9505. https://doi.org/10.1021/acs.jpcc.6b01479.

[113] D. Mora-Fonz, J. Buckeridge, A.J. Logsdail, D.O. Scanlon, A.A. Sokol, S. Woodley, C.R.A. Catlow, Morphological Features and Band Bending at Nonpolar Surfaces of ZnO, J. Phys. Chem. C. 119 (2015) 11598-11611. https://doi.org/10.1021/acs.jpcc.5b01331.

[114] Z.R. Tian, J.A. Voigt, J. Liu, B. Mckenzie, M.J. Mcdermott, M.A. Rodriguez, H. Konishi, H. Xu, Complex and oriented ZnO nanostructures, Nat Mater. 2 (2003) $821-826$. 
[115] L. Vayssieres, Growth of Arrayed Nanorods and Nanowires of $\mathrm{ZnO}$ from Aqueous Solutions, Adv. Mater. 15 (2003) 464-466. https://doi.org/10.1002/adma.200390108.

[116] A. Das, R.G. Nair, Effect of aspect ratio on photocatalytic performance of hexagonal ZnO nanorods, J. Alloys Compd. 817 (2020) 153277. https://doi.org/https://doi.org/10.1016/j.jallcom.2019.153277.

[117] T. Guo, G. Xu, S. Tan, Z. Yang, H. Bu, G. Fang, H. Hou, J. Li, L. Pan, Controllable synthesis of $\mathrm{ZnO}$ with different morphologies and their morphology-dependent infrared emissivity in high temperature conditions, J. Alloys Compd. 804 (2019) 503-510. https://doi.org/https://doi.org/10.1016/j.jallcom.2019.07.011.

[118] S. Liang, X. Gou, J. Cui, Y. Luo, H. Qu, T. Zhang, Z. Yang, Q. Yang, S. Sun, Novel cone-like $\mathrm{ZnO}$ mesocrystals with co-exposed (101) and (000) facets and enhanced photocatalytic activity, Inorg. Chem. Front. 5 (2018) 2257-2267. https://doi.org/10.1039/C8QI00481A.

[119] Effect of Calcination on the Visible Light Photocatalytic Activity of N-Doped TiO2 Prepared by the SolGel Method, J. Nanosci. Nanotechnol. 14 (2014).

[120] P. GonÃ $\mid$ Salves, R. Bertholdo, J.A. Dias, S.C. Maestrelli, T.R. Giraldi, Evaluation of the Photocatalytic Potential of $\mathrm{TiO} 2$ and $\mathrm{ZnO}$ Obtained by Different Wet Chemical Methods, Mater. Res. 20 (2017) 181-189. 